\title{
A Palpable Painless Axillary Mass as the Clinical Manifestation of Castleman's Disease in a Patient with Hepatitis C Disease
}

\author{
Athanasia K. Papazafiropoulou, ${ }^{1}$ Angeliki M. Angelidi, ${ }^{1}$ \\ Antonis A. Kousoulis, ${ }^{2}$ Georgios Christofilidis, ${ }^{1}$ Chariklia Sagia, ${ }^{1}$ Liountmila Kaftanidou, ${ }^{1}$ \\ Kassiani Manoloudaki, ${ }^{3}$ Aikaterini Tsavari, ${ }^{3}$ Georgios Kranidiotis, ${ }^{1}$ \\ Alexandros Kamaratos, ${ }^{1}$ and Andreas Melidonis ${ }^{1}$ \\ ${ }^{1}$ 1st Department of Internal Medicine and Diabetes Center, Tzaneio General Hospital of Piraeus, 18536 Piraeus, Greece \\ ${ }^{2}$ Faculty of Epidemiology and Population Health, London School of Hygiene \& Tropical Medicine, London WC1E 7HT, UK \\ ${ }^{3}$ Department of Pathology, Tzaneio General Hospital of Piraeus, 18536 Piraeus, Greece
}

Correspondence should be addressed to Angeliki M. Angelidi; angieang9@gmail.com

Received 27 December 2015; Accepted 28 April 2016

Academic Editor: Gerald S. Supinski

Copyright (c) 2016 Athanasia K. Papazafiropoulou et al. This is an open access article distributed under the Creative Commons Attribution License, which permits unrestricted use, distribution, and reproduction in any medium, provided the original work is properly cited.

\begin{abstract}
Introduction. Castleman's disease (CD) is a rare lymphoproliferative disorder. $\mathrm{CD}$ is divided into two clinical subtypes: the most common unicentric and the less usual multicentric subtype. The majority of unicentric CD affects the mediastinum, while neck, abdomen, and axilla are less common locations. Case Presentation. Herein, we describe a rare case of unicentric CD in the right axilla in a 36-year-old white male with a medical history of hepatitis $C$ virus infection admitted to our hospital due to palpation of a painless mass in the right axilla. Complete excision of the lesion was performed and, one year after the diagnosis, patient was free of the disease. Conclusions. Although infrequent, it is important to include CD in the differential diagnosis when evaluating axillary lymphadenopathy particularly in young patients with a low-grade inflammation process and chronic disease even in the absence of an abnormal blood picture or organomegaly.
\end{abstract}

\section{Introduction}

Castleman's disease $(\mathrm{CD})$ or angiofollicular lymph node hyperplasia is a rare reactive lymphadenopathy of unknown etiology. Possible pathogenetic factors include follicular dendritic cell dysplasia and immune dysregulation [1]. CD can be divided into two clinical subtypes: the most common unicentric (or localized) and the less common multicentric. Localized disease is presented as lymphadenopathy and usually has a benign course [1]. On the other hand, multicentric disease has a worse prognosis, leading to death by malignancy [1]. CD can also be classified into two major histological variants: hyaline-vascular (HV-CD) and plasma cell variant (PV-CD). The HV-CD variant is more common than the PV$\mathrm{CD}$ [2]. Of the 315 reported cases of unicentric $\mathrm{CD}$ in a French study, $65 \%$ were localized in the mediastinum, $16 \%$ in the neck, $12 \%$ in the abdomen, $3 \%$ in the axilla, and $4 \%$ in diverse locations [3]. Herein, we describe a rare case of unicentric CD in the right axilla in a male patient.

\section{Case Presentation}

A 36-year-old white male was admitted to our hospital due to palpation of a painless mass in the right axilla. The symptoms had presented for approximately a week. His past medical history included intravenous drug addiction (he had stopped use one year prior to admission) and hepatitis $\mathrm{C}$ virus (HCV) infection.

Clinical examination revealed the presence of an enlarged lymph node group in the right axilla and multiple catscratches in his upper extremities. No other palpable lymph nodes were detected in the neck, the left axilla, and inguinal regions. Palpation of the abdomen revealed no tenderness or hepatosplenomegaly. Examination of his cardiovascular 
and respiratory system revealed no pathological signs. His vital signs were blood pressure of $120 / 80 \mathrm{mmHg}$, oxygen saturation of $99 \%$, temperature of $36.6^{\circ} \mathrm{C}$, and heart rate of $72 \mathrm{bpm}$. The remaining laboratory exams were within normal ranges. Computer tomography (CT) scans of the chest and upper and lower abdomen did not reveal any pathologically enlarged lymph nodes or other abnormalities. The initial differential diagnosis included (a) cat-scratch disease (given the contact of the patient with the cat), (b) other bacterial infections (staphylococcus and streptococcus), (c) viral infections (Epstein-Barr virus, cytomegalovirus, and human immunodeficiency virus (HIV)), and (d) neoplastic lymphohyperplastic disorders/lymphomas. Serological tests for Bartonella henselae (immunoglobulin G and M antibodies) were negative. His viral serology was positive for $\mathrm{HCV}$ while negative for HIV and herpesviruses. On the tenth day of hospitalization, a right axillary lymphadenectomy and a biopsy were performed. Histological examination revealed preservation of nodes architecture in the majority of tissue sample. Obliteration of subcapsular sinuses and regressed germinal centers in typically large follicles, some of which with "lollipop" features (onion skin appearance of the mantle zone lymphocytes and sclerotic blood vessels radially traversing into the germinal center), were detected (Figures 1-3). Small number of plasma cells and immunoblasts were observed. These findings set the diagnosis of unicentric HVCD. Patient had an uneventful postoperative course and he was dismissed a week later. One year after diagnosis, a throughout clinical examination and a CT scan were performed showing no evidence of remission of the disease.

\section{Discussion}

$\mathrm{CD}$ is a rare, benign condition that was first described in 1956 in patients with single mediastinal lymph node lymphadenopathy $[1,4]$. The etiology and pathogenesis are unknown but an immunoregulatory abnormality is implicated in its development $[1,4]$. An association of the multicentric type with human herpes virus- (HHV-) 8 infection in HIV-positive patients has been documented and plays an important role in the pathophysiology of the disease [5]. It seems that $C D$ is the result of a chronic low-grade inflammatory process triggered by latent infection with $\mathrm{HHV}-8$, which leads to lymphoid system hyperplasia and also stimulates secretion of interleukin-6 (IL-6) [6].

It has been suggested that $\mathrm{CD}$ lymph node abnormal overgrowth with or without systematic symptoms and organ dysfunction are probably caused by hypersecretion of cytokines. A proposed key pathogenic factor for $\mathrm{CD}$ is the elevated levels of circulating IL-6 [7].

Thus, of interest in this case, while the patient was negative for HHV-8 and HIV infections, his serological tests for $\mathrm{HCV}$ were found positive. Studies have documented the elevated levels of IL-6 in HCV infection $[8,9]$.

However, to the best of our knowledge, there has been no association between HCV infection and CD documented. Extremely few case reports of coexistence of CD (especially the multicentric type of disease) with HCV infection have been published [10-13]. In our case, a potential relationship

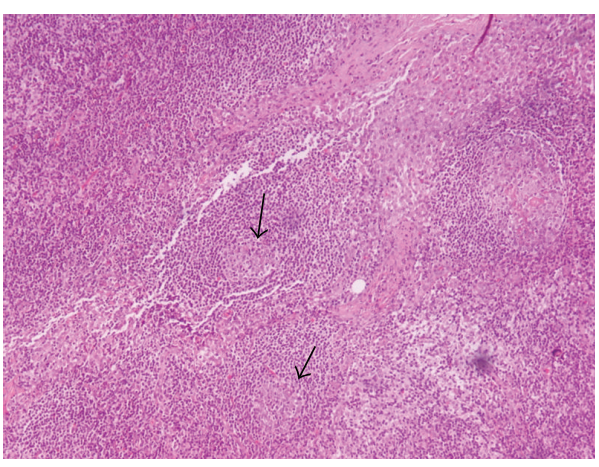

FIGURE 1: Preserved lymph node architecture. Residual follicles with atretic germinal centers.

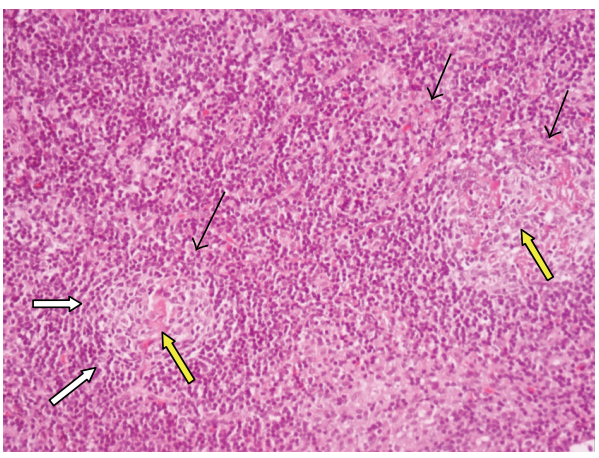

FIGURE 2: H-E regressed germinal centers (black arrows) surrounded by concentric layers of small lymphocytes (white arrows). Two follicles with hyaline-vascular changes (yellow arrow).

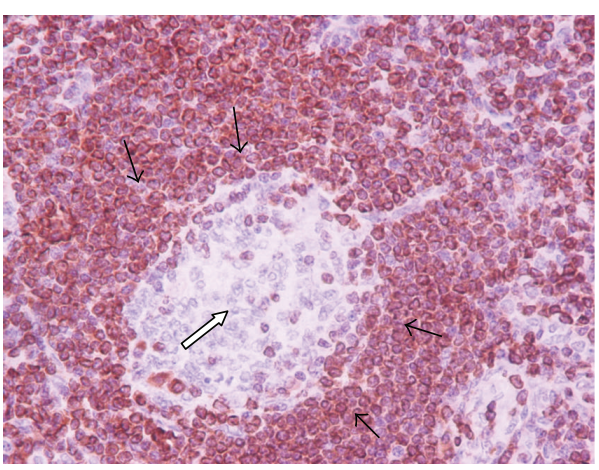

FIGURE 3: Lymphocytes in the mantle zone are positive (black arrows) for Bcl-2 and negative in the small regressed germinal center (white arrows).

of HCV-induced elevated IL-6 levels and the development of the $\mathrm{CD}$ cannot be supported while further investigations and evidence are needed.

Unicentric CD is usually presented as mediastinal, hilar, or intra-abdominal lymphadenopathy $[1,2]$. Primary axillary localization of HV-CD (as in our patient) accounts only for 
$2-3 \%$ of the cases [14-17]. CD affects predominantly young adult patients without gender predominance [2]. Patients are presented with localized mass often detected accidentally or with general symptoms such as fever, night sweats, and weight loss. Symptoms related to compression of adjacent tissues are rarely detected [2].

The most commonly described (77-91\%) symptom of unicentric CD is a mass (usually painless), like in our patient [2]. Common laboratory anomalies include anemia, hypoalbuminemia, polyclonal gammopathy, elevated erythrocyte sedimentation rate or C-reactive protein concentration, and proteinuria [18]. In the present case, patient's laboratory exams were normal. Diagnostic imaging methods such as ultrasound and CT or magnet resonance imaging were not specific. Hence, the gold standard for diagnosis is pathological examination [19].

Treatment of choice for unicentric HV-CD is complete resection, with excellent long-term prognosis (5-year survival rate of nearly $100 \%$ ) and uncommon relapse $[1,20]$. However, patients may develop malignant neoplasms, such as follicular dendritic cell sarcomas or vascular neoplasms, associated with HV-CD [20]. Radiotherapy has also been reported to be effective in some patients with a variable response rate and usually administered to alienate compressive symptoms [21].

\section{Conclusions}

In conclusion, primary axillary localization of $\mathrm{CD}$ is a rare but possible cause of peripheral lymphadenopathy. Although infrequent, it is important to include CD in the differential diagnosis when evaluating axillary lymphadenopathy particularly in young patients with a low-grade inflammation process and chronic disease even in the absence of an abnormal blood picture or organomegaly.

\section{Consent}

Written informed consent was obtained from the patient for publication of this case report and any accompanying images.

\section{Competing Interests}

The authors declare that there are no competing interests regarding the publication of this paper.

\section{Authors' Contributions}

Athanasia K. Papazafiropoulou and Angeliki M. Angelidi performed the literature review, composed this case report, and wrote the paper. Antonis A. Kousoulis, Georgios Christofilidis, Chariklia Sagia, Liountmila Kaftanidou, Kassiani Manoloudaki, Aikaterini Tsavari, and Georgios Kranidiotis were involved in the collection and assembly of the data. Alexandros Kamaratos and Andreas Melidonis corrected and approved the final version of the paper. All the authors read and approved the final paper. Athanasia K. Papazafiropoulou and Angeliki M. Angelidi contributed equally to this work.

\section{References}

[1] W. B. Bowne, J. J. Lewis, D. A. Filippa et al., "The management of unicentric and multicentric Castleman's disease: a report of 16 cases and a review of the literature," Cancer, vol. 85, no. 3, pp. 706-717, 1999.

[2] A. R. Keller, L. Hochholzer, and B. Castleman, "Hyalinevascular and plasma-cell types of giant lymph node hyperplasia of the mediastinum and other locations," Cancer, vol. 29, no. 3, pp. 670-683, 1972.

[3] P. Testa, A. Pigne, A. Voinnesson, A. Vieillefond, and J. Paillas, "Les hyperplasies lymphoïdes angiofolliculaires (maladie de Castleman) Premiere localisation meso-sigmoïdienne," Chirurgie, vol. 106, pp. 156-160, 1980.

[4] M. J. McCarty, S. J. Vukelja, P. M. Banks, and R. B. Weiss, "Angiofollicular lymph node hyperplasia (Castleman's disease)," Cancer Treatment Reviews, vol. 21, no. 4, pp. 291-310, 1995.

[5] J. Soulier, L. Grollet, E. Oksenhendler et al., "Kaposi’s sarcomaassociated herpesvirus-like DNA sequences in multicentric Castleman's disease," Blood, vol. 86, no. 4, pp. 1276-1280, 1995.

[6] C. Larroche, P. Cacoub, and P. Godeau, "Castleman's disease," Revue de Medecine Interne, vol. 17, no. 12, pp. 1003-1013, 1996.

[7] B. Ahmed, J. A. Tschen, P. R. Cohen, M. H. Zaki, P. L. Rady, S. K. Tyring et al., "Cutaneous castleman's disease responds to antiinterleukin-6 treatment," Molecular Cancer Therapeutics, vol. 6, no. 9, pp. 2386-2390, 2007.

[8] M. L. Salter, B. Lau, S. H. Mehta, V. F. Go, S. Leng, and G. D. Kirk, "Correlates of elevated interleukin-6 and C-reactive protein in persons with or at high risk for HCV and HIV infections," Journal of Acquired Immune Deficiency Syndromes, vol. 64, no. 5, pp. 488-495, 2013.

[9] Y. Oyanagi, T. Takahashi, S. Matsui et al., "Enhanced expression of interleukin-6 in chronic hepatitis C," Liver, vol. 19, no. 6, pp. 464-472, 1999.

[10] J. A. Yates, N. A. Zakai, R. C. Griffith, E. J. Wing, and F. J. Schiffman, "Multicentric Castleman disease, Kaposi sarcoma, hemophagocytic syndrome, and a novel HHV8lymphoproliferative disorder," AIDS Read, vol. 17, no. 12, pp. 596-601, 2007.

[11] S.-P. Chou, L.-K. Chen, S.-S. Lo, A. F.-Y. Li, F.-C. Chang, and S.-J. Hwang, "Hyaline-vascular variant of Castleman's disease mimicking a gastric submucosal tumor," Journal of the Chinese Medical Association, vol. 67, no. 3, pp. 152-155, 2004.

[12] A. Slotwiner, C. P. Garwacki, and S. Moll, "Castleman's disease," American Journal of Hematology, vol. 73, no. 1, pp. 64-65, 2003.

[13] R. Simko, K. Nagy, B. Lombay et al., "Multicentric Castleman disease and systemic lupus erythematosus phenotype in a boy with Klinefelter syndrome: long-term disease stabilization with interferon therapy," Journal of Pediatric Hematology/Oncology, vol. 22, no. 2, pp. 180-183, 2000.

[14] J. M. Elizalde, B. Eizaguirre, and J. I. Lopez, "Angiofollicular giant lymph node hyperplasia that presented with an axillary mass," European Journal of Surgery, vol. 159, pp. 183-184, 1993.

[15] E. C. Paraskevaides and M. C. Wilson, "Massive axillary lymphnode hyperplasia in pregnancy: a case report," European Journal of Obstetrics and Gynecology and Reproductive Biology, vol. 29, no. 4, pp. 353-355, 1988.

[16] G. Selva, M. Imbriaco, A. Riccardi, L. Sparano, and A. Sodano, "Angiofollicular lymphoid hyperplasia (Castleman disease) of axillary localization. A case," La Radiologia Medica, vol. 100, pp. 290-292, 2000. 
[17] J. Herrada, F. Cabanillas, L. Rice, J. Manning, and W. Pugh, "The clinical behavior of localized and multicentric Castleman disease," Annals of Internal Medicine, vol. 128, no. 8, pp. 657-662, 1998.

[18] T. J. Kim, J. K. Han, Y. H. Kim, T. K. Kim, and B. I. Choi, "Castleman disease of the abdomen: imaging spectrum and clinicopathologic correlations," Journal of Computer Assisted Tomography, vol. 25, no. 2, pp. 207-214, 2001.

[19] Y. Yamashita, R. Hirai, T. Matsukawa, I. Ogata, and M. Takahashi, "Radiological presentations of Castleman's disease," Computerized Medical Imaging and Graphics, vol. 17, no. 2, pp. 107-117, 1993.

[20] P. Bucher, G. Chassot, G. Zufferey, F. Ris, O. Huber, and P. Morel, "Surgical management of abdominal and retroperitoneal Castleman's disease," World Journal of Surgical Oncology, vol. 3, article 33, 2005.

[21] G. M. Chronowski, C. S. Ha, R. B. Wilder, F. Cabanillas, J. Manning, and J. D. Cox, "Treatment of unicentric and multicentric Castleman disease and the role of radiotherapy," Cancer, vol. 92, no. 3, pp. 670-676, 2001. 


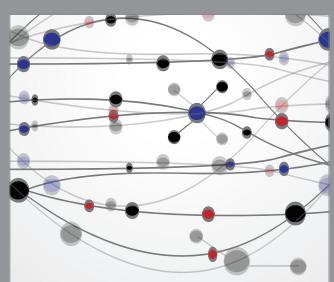

The Scientific World Journal




Gastroenterology Research and Practice

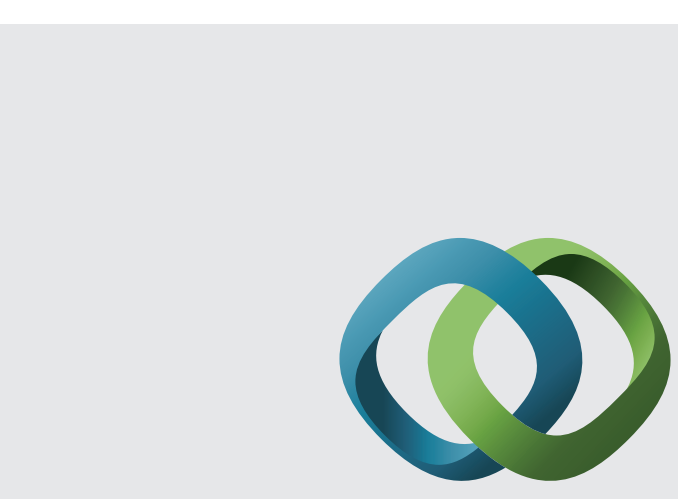

\section{Hindawi}

Submit your manuscripts at

http://www.hindawi.com
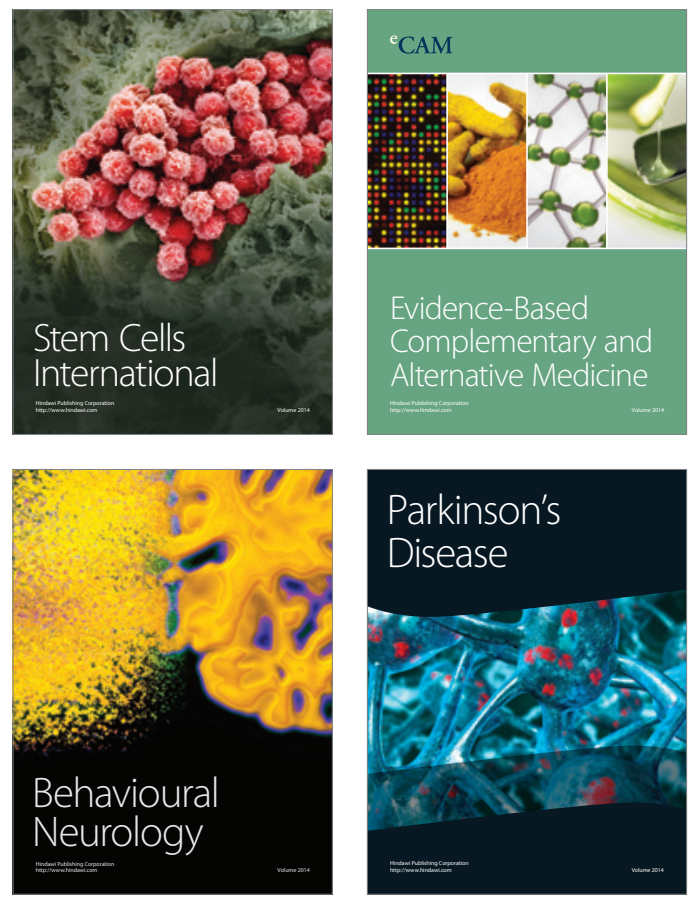


Disease Markers
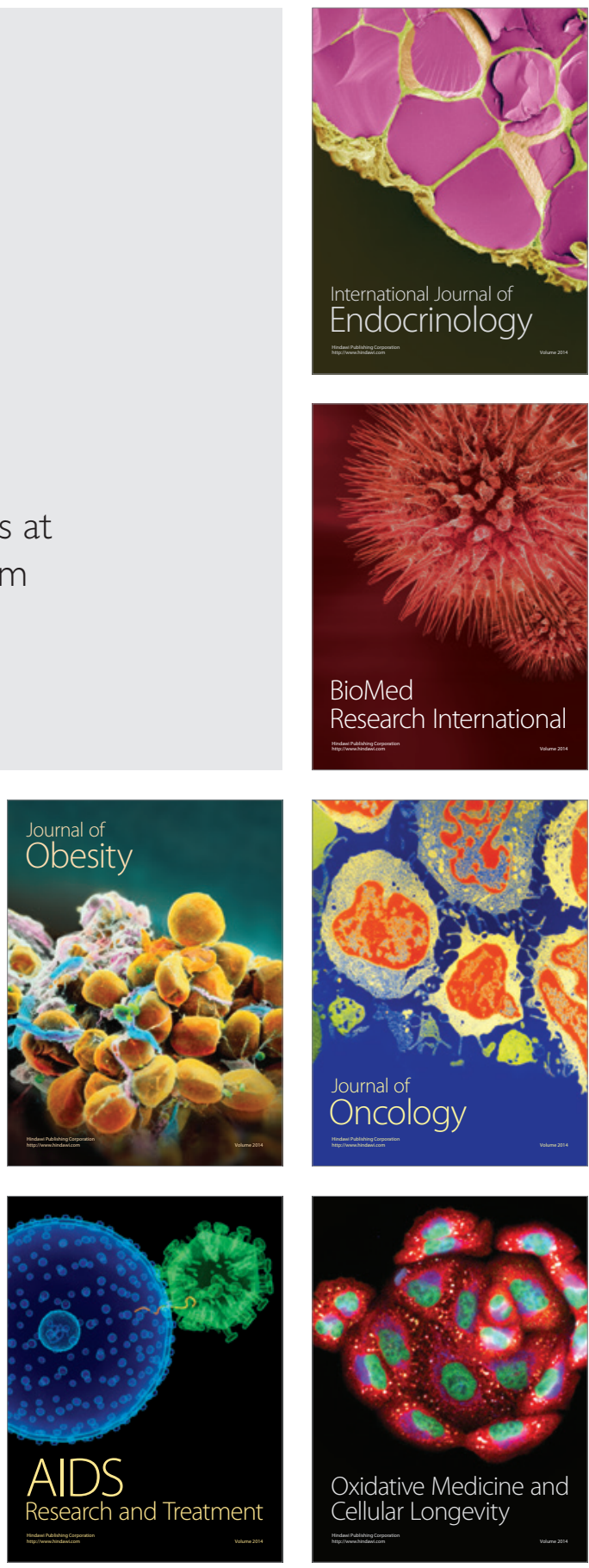